\title{
Mycoplasma pneumoniae infections, 11 countries in Europe and Israel, 2011 to 2016
}

Michael L Beeton ${ }^{1}$, Xu-Sheng Zhang ${ }^{2}$, Søren A Uldum³, Cécile Bébéar4, Roger Dumke5, Karolina Gullsby ${ }^{6}$, Margareta leven7,

Katherine Loens ${ }^{7}$, Ran Nir-Paz ${ }^{8}$, Sabine Pereyre ${ }^{4}, 0$ Brad Spiller', Victoria J Chalker ${ }^{2}$, the ESCMID Study Group for Mycoplasma

and Chlamydia Infections (ESGMAC) Mycoplasma pneumoniae subgroup ${ }^{10}$

1. Department of Biomedical Sciences, Cardiff Metropolitan University, Cardiff, United Kingdom

2. Public Health England, London, United Kingdom

3. Department of Bacteria, Parasites and Fungi, Statens Serum Institut, Copenhagen, Denmark

4. USC-EA 3671, Mycoplasmal and Chlamydia Infections in Humans, University of Bordeaux, Bordeaux, France

5. TU Dresden, Dresden, Germany

6. Centre for Research and Development, Uppsala University/Region Gävleborg, Gävle, Sweden

7. Antwerp University Hospital Edegem, Belgium

8. Department of Clinical Microbiology and Infectious Diseases, Hadassah-Hebrew University Medical Center, Jerusalem, Israel

9. Department of Medical Microbiology, Division of Infection and Immunity, Cardiff University, School of Medicine, Cardiff, United Kingdom

10. ESCMID Study Group for Mycoplasma and Chlamydia Infections (ESGMAC) Mycoplasma pneumoniae subgroup members are listed at the end of the article

Correspondence: Victoria Chalker (vicki.chalker@phe.gov.uk)

Beeton Michael L, Zhang Xu-Sheng, Uldum Søren A, Bébéar Cécile, Dumke Roger, Gullsby Karolina, leven Margareta, Loens Katherine, Nir-Paz Ran, Pereyre

Sabine, Spiller O Brad, Chalker Victoria J, the ESCMID Study Group for Mycoplasma and Chlamydia Infections (ESGMAC) Mycoplasma pneumoniae subgroup.

Mycoplasma pneumoniae infections, 11 countries in Europe and Israel, 2011 to 2016. Euro Surveill. 2020;25(2):pii=1900112. https://doi.org/10.2807/1560-7917.

ES.2020.25.2.1900112

Article submitted on 11 Feb 2019 / accepted on 15 Jul 2019 / published on 16 Jan 2020

Background: Mycoplasma pneumoniae is a leading cause of community-acquired pneumonia, with large epidemics previously described to occur every 4 to 7 years. Aim: To better understand the diagnostic methods used to detect $M$. pneumoniae; to better understand $M$. pneumoniae testing and surveillance in use; to identify epidemics; to determine detection number per age group, age demographics for positive detections, concurrence of epidemics and annual peaks across geographical areas; and to determine the effect of geographical location on the timing of epidemics.

Methods: A questionnaire was sent in May 2016 to Mycoplasma experts with national or regional responsibility within the ESCMID Study Group for Mycoplasma and Chlamydia Infections in 17 countries across Europe and Israel, retrospectively requesting details on $M$. pneumoniae-positive samples from January 2011 to April 2016. The Moving Epidemic Method was used to determine epidemic periods and effect of country latitude across the countries for the five periods under investigation. Results: Representatives from 12 countries provided data on $M$. pneumoniae infections, accounting for 95,666 positive samples. Two laboratories initiated routine macrolide resistance testing since 2013. Between 2011 and 2016, three epidemics were identified: 2011/12, 2014/15 and 2015/16. The distribution of patient ages for $M$. pneumoniae-positive samples showed three patterns. During epidemic years, an association between country latitude and calendar week when epidemic periods began was noted.
Conclusions: An association between epidemics and latitude was observed. Differences were noted in the age distribution of positive cases and detection methods used and practice. A lack of macrolide resistance monitoring was noted.

\section{Introduction}

Mycoplasma pneumoniae is a major cause of respiratory infection in humans and macrolide antibiotics, such as azithromycin, are used as the first-line of treatment in many countries. The bacterium is transmitted from person-to-person by respiratory droplets with the incubation period ranging from 4 days to 3 weeks [1]. Because of M. pneumoniae's intrinsic resistance to many antibiotics, including all cell wall inhibitors, macrolide antibiotics such as azithromycin and clarithromycin are the drug of choice for treatment. In cases of suspected infection in immunocompromised individuals, bactericidal fluoroquinolones may be considered. Tetracyclines are an alternative for treatment of adults with possible macrolide-resistant M. pneumoniae infections. Prudent use of antibiotics has been urged for all cases of $M$. pneumoniae infection because of worldwide reports of macrolide resistance, which have been reported as ranging from $0.2 \%$ in Sweden to more than $90 \%$ in China [2-5].

M. pneumoniae infections show seasonal variation. In temperate climates, the number of infections peak during the latter months of the years, with epidemic periods every 4 to 7 years on average [6-8]. The most 
Mycoplasma pneumoniae detection methods, percent of positive samples and macrolide resistance monitoring by country, 11 countries in Europe and Israel, 2011-2016

\begin{tabular}{|c|c|c|c|c|c|c|c|c|c|c|}
\hline \multirow[b]{2}{*}{ Country } & \multicolumn{2}{|c|}{$\begin{array}{c}\text { Nucleic acid } \\
\text { amplification test }\end{array}$} & \multicolumn{2}{|c|}{ Culture } & \multicolumn{2}{|c|}{ Serology } & \multirow{2}{*}{$\begin{array}{l}\text { Total } \\
\text { number } \\
\text { of } \\
\text { positive } \\
\text { samples }\end{array}$} & \multirow{2}{*}{$\begin{array}{c}\text { Total } \\
\text { number } \\
\text { of } \\
\text { negative } \\
\text { samples }\end{array}$} & \multirow{2}{*}{$\begin{array}{l}\text { Percent of } \\
\text { positive } \\
\text { samples } \\
(\%)\end{array}$} & \multirow{2}{*}{$\begin{array}{l}\text { Macrolide } \\
\text { resistance } \\
\text { monitoring }\end{array}$} \\
\hline & Performed & $\begin{array}{l}\text { Number of } \\
\text { positive } \\
\text { detections }\end{array}$ & Performed & $\begin{array}{l}\text { Number of } \\
\text { positive } \\
\text { detections }\end{array}$ & Performed & $\begin{array}{l}\text { Number of } \\
\text { positive } \\
\text { detections }\end{array}$ & & & & \\
\hline Belgium & Yes & 894 & Yes & 49 & Yes & 12,047 & $21,094^{a}$ & ND & NA & $\begin{array}{c}\text { Only monitored } \\
\text { when samples } \\
\text { test positive } \\
\text { at the NRC. } \\
\text { No testing } \\
\text { in sentinel } \\
\text { laboratories. }\end{array}$ \\
\hline Denmark & Yes & 20,081 & No & NA & No & NA & 20,081 & 264,770 & 7.0 & $\begin{array}{c}\text { No routine } \\
\text { surveillance } \\
\text { system in place. } \\
\text { In } 2010 / 11, \\
2011 / 12 \text { and } \\
2015 / 16,809 \\
\text { samples were } \\
\text { examined } \\
\text { identifying } \\
13 \text { macrolide } \\
\text { resistance- } \\
\text { associated } \\
\text { mutations } \\
\text { (1.5\%). Samples } \\
\text { are investigated } \\
\text { upon physician } \\
\text { request. }\end{array}$ \\
\hline France & Yes & 92 & Yes & $53^{b}$ & Yes & 298 & 390 & 7,463 & 5.0 & $\begin{array}{c}\text { Performed } \\
\text { on all clinical } \\
\text { specimens } \\
\text { detected as } M \text {. } \\
\text { pneumoniae- } \\
\text { positive by } \\
\text { NAAT since } \\
2013 \text { [13]. }\end{array}$ \\
\hline Germany & Yes & 127 & No & NA & Yes & 316 & 443 & 10,143 & 4.2 & No comment \\
\hline Greece & No & NA & No & NA & Yes & 140 & 140 & 1,498 & 8.5 & $\begin{array}{l}\text { Information not } \\
\text { provided }\end{array}$ \\
\hline Hungary & Yes & 17 & No & NA & Yes & 1,117 & 1,134 & 6,109 & 15.7 & $\begin{array}{l}\text { Information not } \\
\text { provided }\end{array}$ \\
\hline Ireland & No & NA & No & NA & Yes & 535 & 535 & 2,853 & 15.8 & $\begin{array}{l}\text { Information not } \\
\text { provided }\end{array}$ \\
\hline Israel & Yes & 848 & No & NA & No & NA & 848 & 5,309 & 13.8 & $\begin{array}{c}\text { No active } \\
\text { monitoring. }\end{array}$ \\
\hline Norway & Yes & 13,980 & No & NA & Yes & 10,678 & 24,658 & ND & NA & $\begin{array}{l}\text { Information not } \\
\text { provided }\end{array}$ \\
\hline Slovenia & Yes & 1,172 & Yes & 827 & No & NA & 1,172 & 8,872 & 11.7 & $\begin{array}{l}\text { Only upon } \\
\text { physician } \\
\text { request }\end{array}$ \\
\hline Sweden & Yes & 9,499 & No & NA & Yes & 10,024 & 19,523 & 169,501 & 10.3 & $\begin{array}{l}\text { No active } \\
\text { monitoring. }\end{array}$ \\
\hline $\begin{array}{l}\text { United } \\
\text { Kingdom } \\
\text { (excluding } \\
\text { Northern } \\
\text { Ireland) }\end{array}$ & Yes & 385 & No & NA & Yes & 5,263 & 5,648 & ND & NA & $\begin{array}{l}\text { No national } \\
\text { system. All } \\
\text { positive } \\
\text { samples } \\
\text { referred to PHE } \\
\text { are tested. }\end{array}$ \\
\hline Total & NA & 47,095 & NA & 876 & NA & 40,418 & 95,666 & 476,518 & NA & NA \\
\hline
\end{tabular}

NA: not applicable; NAAT: Nucleic acid amplification test; ND: no data available; NRC: National Reference Centre; PHE: Public Health England.

${ }^{a}$ Method of detection not known for sentinel laboratories.

${ }^{\mathrm{b}}$ Not included in the overall total for the purpose of de-duplication as these 53 samples were already listed in NAAT or serological counts.

Responses were received to state $M$. pneumoniae testing and surveillance is not in place on a national scale or case data were not available within the timespan of the survey from European Society of Clinical Microbiology and Infectious Diseases (ESCMID) Study Group for Mycoplasma Infections (ESGMI) members from Cyprus, Malta, the Netherlands, Poland, Slovakia or Spain. 


\section{FIGURE 1}

Four weekly moving average data on Mycoplasma pneumoniae infections by detection methods, 11 countries in Europe and Israel, 2011-2016
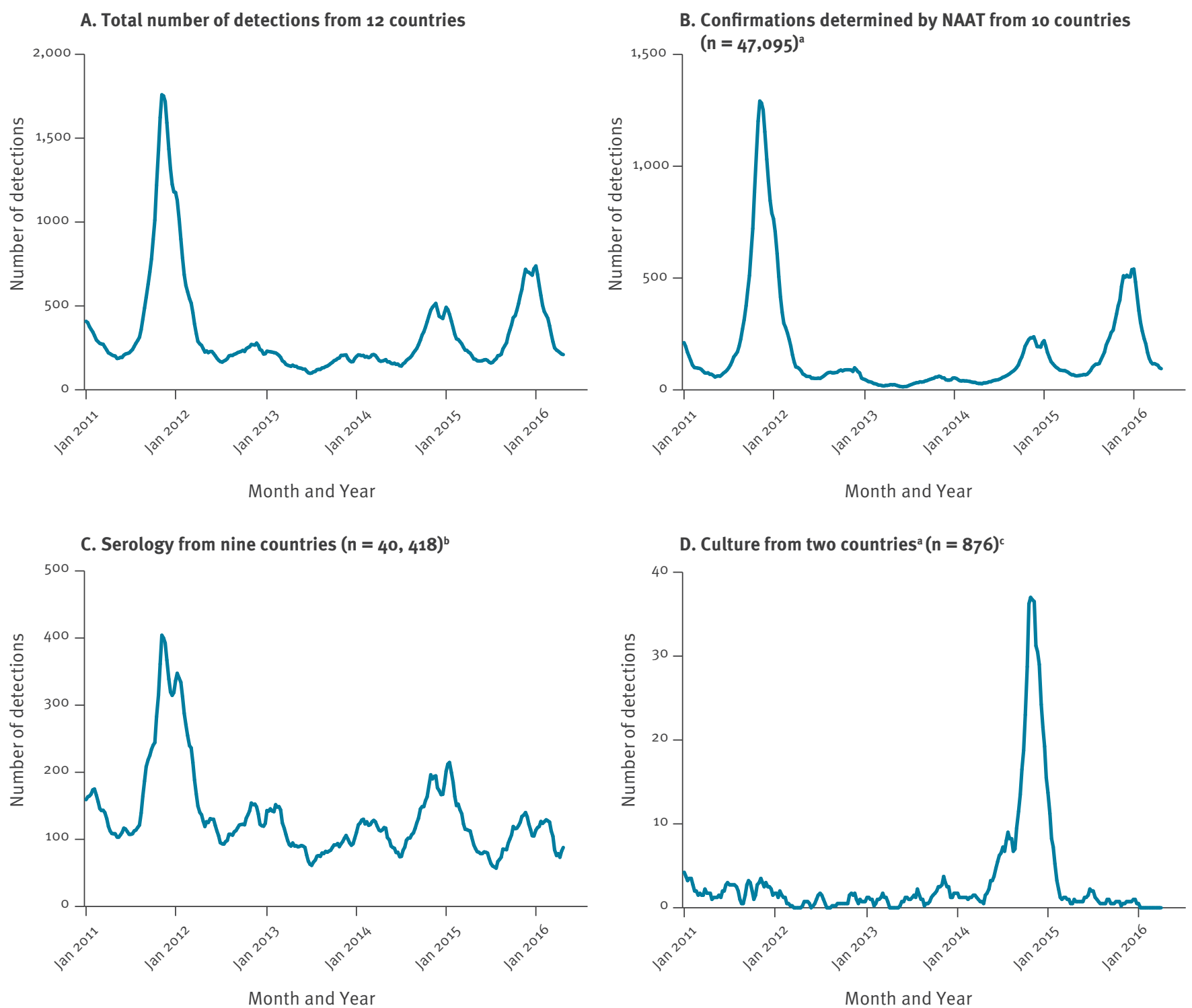

NAAT: nucleic acid amplification tests.

a Ten countries: Belgium, Denmark, France, Germany, Hungary, Israel, Norway, Slovenia, Sweden and the United Kingdom (excluding Northern Ireland).

${ }^{b}$ Nine countries: Belgium, France, Germany, Greece, Hungary, Ireland, Norway and Sweden and the United Kingdom (excluding Northern Ireland).

c Two countries: Belgium and Slovenia. Culture data from France not included as it was duplicated in NAAT and serological data. 
recent survey in 2012 by Lenglet et al indicated that some countries in the European Union and European Economic Area experienced an increase in M. pneumoniae cases in 2011 whereas others did not, indicating that a universal geographic increase had not occurred [5]. Little is understood about the transmission of $M$. pneumoniae within populations and several factors have been postulated to account for transmission dynamics, including the immunity level of the population, the bacterial population based on the $P_{1}$ adhesin type, the age and extent of mixing of children in educational settings.

Methodologies for detection of M. pneumoniae include nucleic acid amplification tests (NAAT), serology and culture with varying sensitivities and specificities. There is no international standard material for quality control detection in assays, although external quality control schema exist for some methodologies (NAAT). There are no internationally defined guidelines on the requirements for surveillance of $M$. pneumoniae, macrolide resistance testing and surveillance, reference system structure, routine testing and bacterial strain discrimination. However, a few countries such as France and the United States (US) have surveillance within specific regions and national surveillance is seen in countries such as Denmark [9] and Japan, the latter of which has maintained an active surveillance system for this pathogen for some time [10]. Overall, laboratory confirmed cases and surveillance data regarding the number of cases and reported cases of macrolide resistance are likely to be underestimated. This is further confounded because an undefined proportion of patients will have mild disease or may be carriers within community settings, without active testing to confirm the infection. Further underestimation is likely to occur from patients receiving empirical treatment in the absence of laboratory-confirmed infection with M. pneumoniae.

In response to an increase in infection seen in several countries in 2016, the European Society of Clinical Microbiology and Infectious Diseases (ESCMID) Study Group for Mycoplasma Infections (ESGMI), now called the Study Group for Mycoplasma and Chlamydia Infections (ESGMAC), established this study [9,11]. The purpose of the study was to gain a greater understanding of the diagnostic methods used to detect M. pneumoniae; gain a greater understanding of the testing and surveillance in use for M. pneumoniae (macrolide resistance, seasonality); to identify epidemics; to determine detections per age group, age demographics for positive detections and concurrence of epidemics and annual peaks across geographical areas; and to determine the effect of geographical location on timing of epidemics.

\section{Methods}

Study type, data collection and analysis

ESGMI conducted a retrospective email-based survey in May 2016 of ESGMI members in countries in Europe and Israel, asking members to describe existing laboratory-confirmed case data for M. pneumoniae infection. This retrospective study involved sending an emailbased survey to 18 experts collating laboratory-confirmed documented detections of $M$. pneumoniae from national laboratory and surveillance institutions or, if not available, other regional laboratory and surveillance institutions. Mycoplasma experts invited to participate in the study were either active members of ESGMI or authors listed in the previous study by Lenglet et al [5]. Participants were invited to join the study and provide the number of detections confirmed by nucleic acid amplification test (NAAT), serology, culture and total overall between weeks commencing 3 January 2011 to 24 April 2016. Positive results and, if available, negative results were also collated. For Germany and France, only regional data were available. Additional information was requested, including what diagnostic methods were used to detect $M$. pneumoniae; whether surveillance for M. pneumoniae was in use; if macrolide resistance was being monitored by countries; and M. pneumoniae detection number per age group.

Data from each participating country was collated and aggregated to give total number of detections per age group and four weekly moving averages of detections per country and overall where possible. We did not request information on the sex of patient from which detections were made. Total weekly data were subcategorised by age group: 0 to 4 years, 5 to 9 years, 10 to 14 years, 15 to 24 years, 25 to 44 years, 45 to 64 years, $\geq 65$ years or unknown.

\section{Case definition}

Cases of $M$. pneumoniae infection were defined by local practice. Because of local variation, this study collated information on M. pneumoniae detections, not cases.

\section{De-duplication and exclusion criteria}

Because of the heterogeneous nature of $M$. pneumoniae data collection from each country, defining study-wide de-duplication criteria was not feasible. Participants were therefore asked to detail if data with duplicate samples from the same patient (e.g. with NAAT and serology) was included as a single category and if possible, to include as serology. Specific exclusion criteria were also not set for similar reasons stated above. Responses for de-duplication and exclusion criteria are listed in Supplementary Table S1.

Characteristics of epidemics using the Moving Epidemic Method

To determine the characteristic properties of $M$. pneumoniae epidemics across the 12 countries for which 


\section{FIGURE 2}

Analysis of Mycoplasma pneumoniae epidemic periods using the Moving Epidemic Method, 11 countries in Europe and Israel, 2011-2016

A. Week 19 2011-week 182012 (epidemic year) $(n=35,747)$

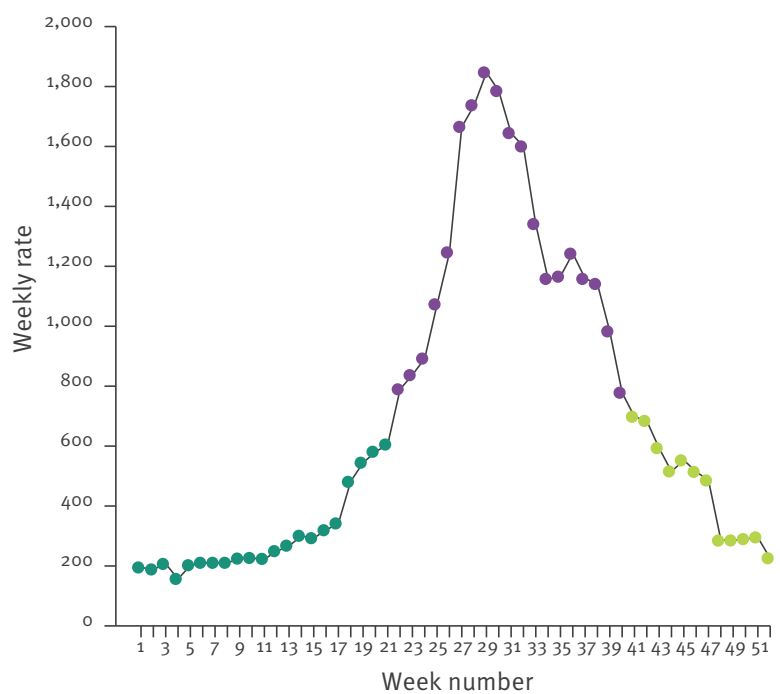

C. Week 19 2013-week $182014(n=8,510)$

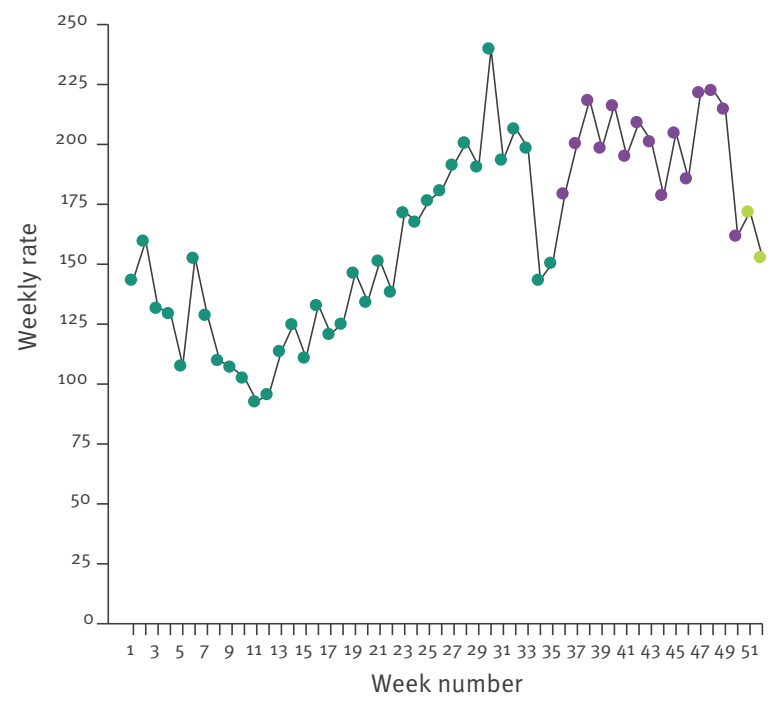

E. Week 19 2015-week 172016 (epidemic year) $(n=19,439)$

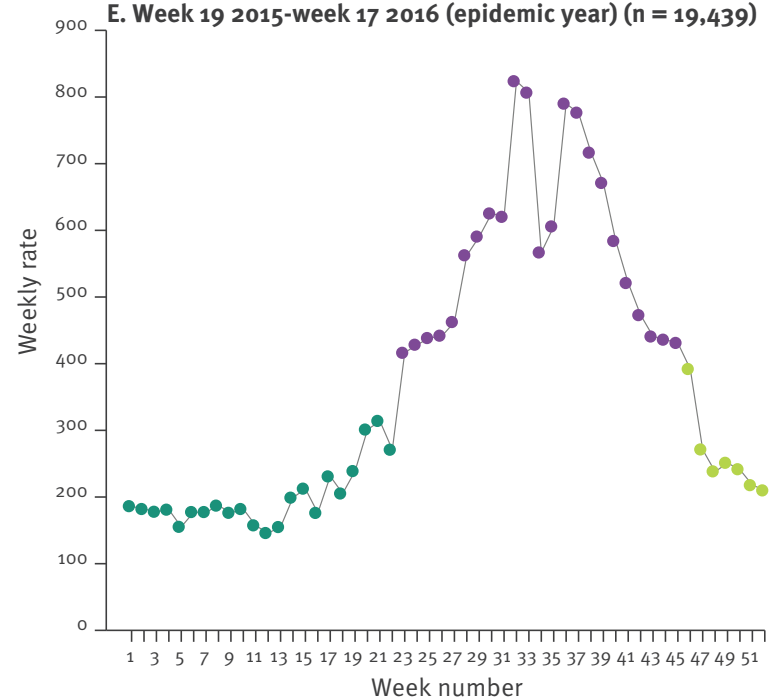

B. Week 19 2012- week $182013(n=11,089)$

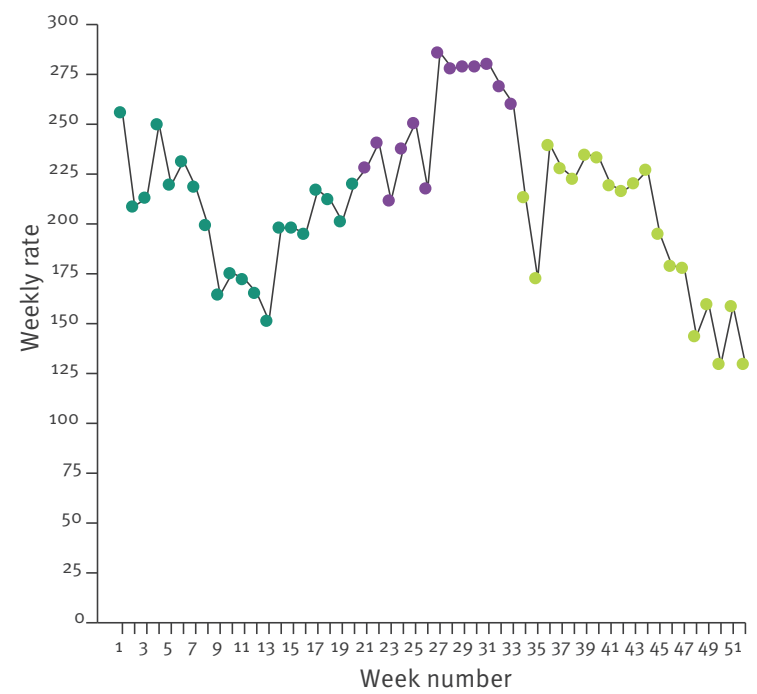

D. Week 19 2014-week 182015 (epidemic year) $(n=15,312)$

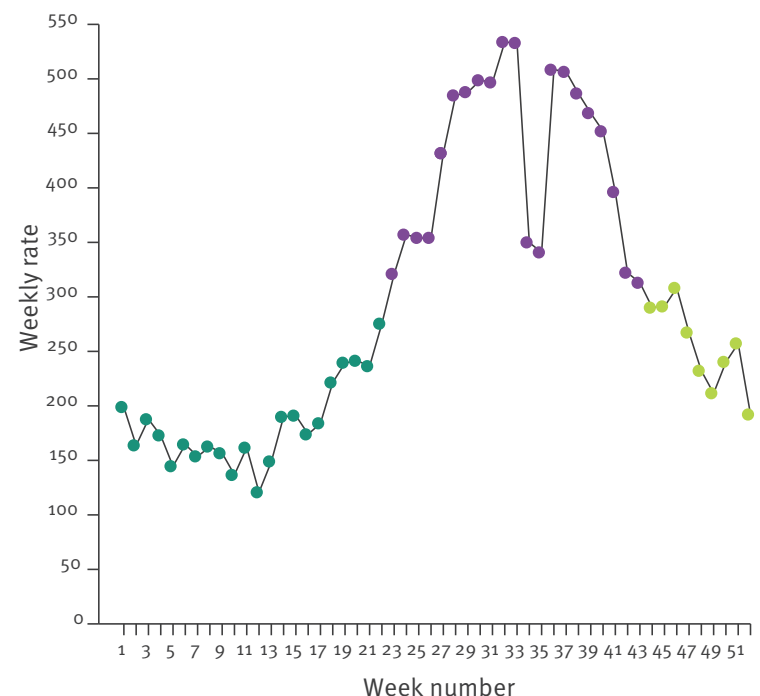

Week number

MEM: Moving Epidemic Method.

Week numbers represent epidemic week period (week 1 represents calendar week 19). Green dots represent pre-epidemic period, purple dots represent epidemic period and yellow dots represent post-epidemic period, as calculated by the MEM. 


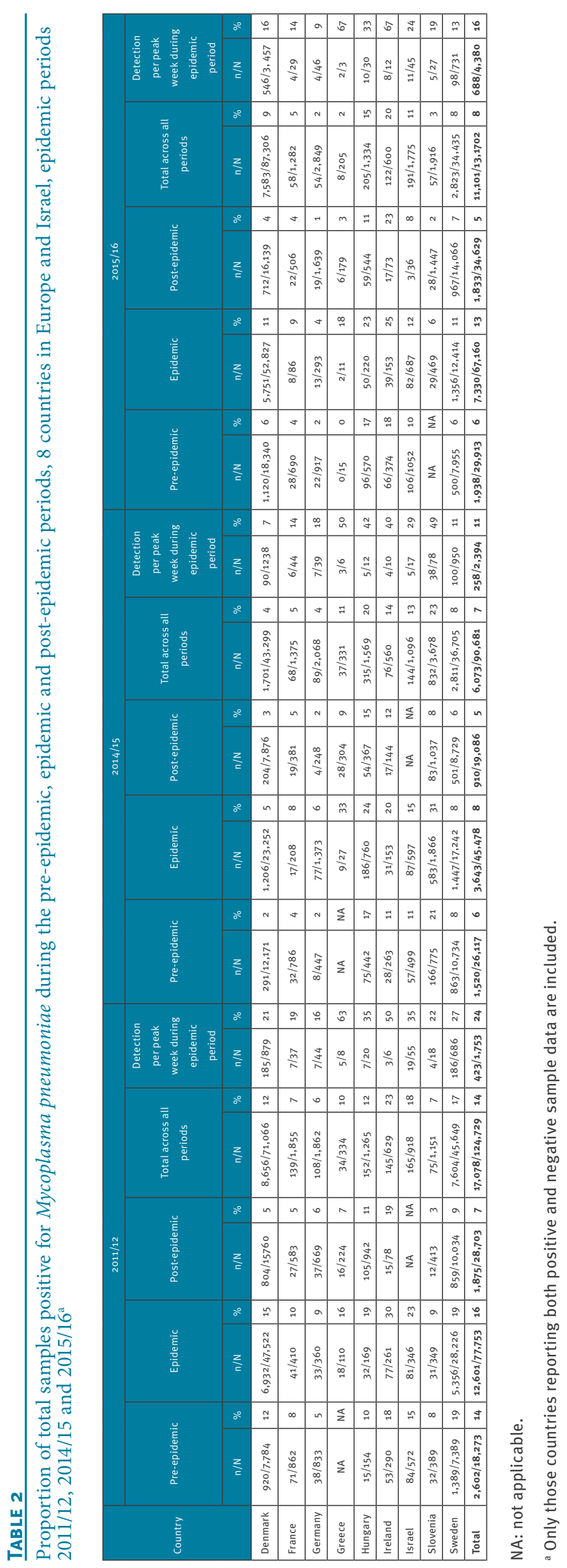


data were provided on $M$. pneumoniae positivity, the Moving Epidemic Method (MEM) was used [12]. An epidemic slope threshold of $2 \%$ was chosen and used to determine the pre-epidemic period, epidemic period and post-epidemic period for the five periods coinciding with annual peaks spanning week 19 of the first year through week 18 of the following year. These data were used to calculate the epidemic duration for each country, as well as the percentage of positive samples that were identified within this period. Data generated from the MEM model, such as week number in which epidemics began, were used to correlate the onset of epidemics with the geographical location of each country. Statistical analysis for generating $p$ values and calculation of $r^{2}$ were performed with GraphPad Prism 5.0.

\section{Ethics statement}

This retrospective study involved collation of anonymised surveillance data for epidemiological analysis. Ethical approval was not required and no patient identifiers were included in the study.

\section{Results}

Of the 18 countries approached, 11 countries across Europe and Israel, provided information regarding $M$. pneumoniae. For Cyprus, Malta, the Netherlands, Poland, Slovakia and Spain, M. pneumoniae national testing and surveillance systems were not in place or a response with data was not received within the timeframe of the study.

\section{Mycoplasma pneumoniae detection methods}

During the study period, a total of 95,666 detections of $M$. pneumoniae were confirmed from participating countries (Table 1). The method of $M$. pneumoniae detection varied between the 12 countries. Two countries, Denmark and Israel, reported exclusively NAAT use; two countries, Greece and Ireland, reported serology exclusively; five countries, Germany, Hungary, Norway, Sweden and the United Kingdom (excluding Northern Ireland) used a combination of NAAT and serology; one country, Slovenia, used NAAT in combination with culture; and two countries, Belgium and France, used all three methods. No country relied on culture alone (Table 1).

The greatest number of positive samples were reported using NAAT $(47,095 ; 49 \%)$ followed by serology (40,418; 42\%). Only 876 (1\%) samples were reported positive by culture and 7,277 (8\%) of tests were not specified. Norway contributed the greatest number of $M$. pneumoniae-positive detections to the total figure $(24,658 ; 26 \%)$ and Greece the lowest (140; $0.1 \%)$. De-duplication data were determined at country level (Supplementary Table S1).

\section{Macrolide resistance monitoring}

With regards to active monitoring of macrolide resistance, five countries did not comment; Belgium noted that monitoring was only carried out on positive samples identified at the National Reference Laboratory, but not at sentinel laboratories; Slovenia noted that macrolide resistance determination was carried out only upon physician request; in this study, Denmark stated that NAAT-positive samples from three recent $M$. pneumoniae epidemic periods were investigated, finding a low level (1.5\%) of macrolide resistance, and that clinical samples are investigated on request from physicians; the Mycoplasmal and Chlamydia Infections in Humans Research Department, University of Bordeaux, France initiated national systematic monitoring of all NAAT-positive clinical specimens in 2013 using an in-house published method [13]. In 2017, England and Wales introduced monitoring of all positive NAAT samples referred to the National Reference Laboratory. Two countries stated that no monitoring for resistance was in place (Table 1 ).

Total number of detections and seasonality The distribution and seasonality of the 95,666 detections from the 12 countries across the study period was determined. To account for weekly bias in reporting, data were converted to four weekly moving average. The greatest number of positive samples from the four weekly moving average data was 1,759 positive detections during week 48 of 2011.

Detection of $M$. pneumoniae by NAAT correlated with the overall detections (Figure $1 \mathrm{~A}$ and Figure $1 \mathrm{~B}$ ). Detection of $M$. pneumoniae by culture accounted for the lowest number of positive samples per methodology; $1 \%$ of the total positive samples. Detection using serology was the second most common method for detecting $M$. pneumoniae-positive patients (Figure $1 \mathrm{C}$ ). The four weekly moving average for detection by culture (Figure 1D) was less than five positive samples for all reporting weeks with the exception of Slovenia in the 2015 season when a maximum average of 52 positive samples was identified.

\section{Epidemic periods based on the Moving Epidemic Method}

Analysis of detections during the annual periods was carried out using MEM (Figure 2). For the five annual periods described, we noted 35,$747 ; 11,089 ; 8,510$; 15,312 ; 19,439 detections for the periods 2011/12, $2012 / 13,2013 / 14,2014 / 15$ and 2015/16, respectively. Three epidemics were detected between 2011/12, $2014 / 15$ and $2015 / 16$, in which $67 \%, 59 \%$ and $68 \%$ of each period's detections were identified during the calculated epidemic period, respectively. Epidemics had longer duration, 19, 21 and 23 weeks, respectively, compared with the duration observed during annual seasonal peaks of infection (non-epidemic periods). In $2012 / 13$, the duration was 13 weeks with $30 \%$ of total detections and in 2013/14, 15 weeks with $35 \%$ of total detections. For countries providing the total number of negative samples, the percentage of positive samples identified during the pre-epidemic, epidemic and post-epidemic period was calculated for the epidemic periods of 2011/12, 2014/15 and 2015/16 (Table 2). For all periods, there was a greater percentage of positive 


\section{FIGURE 3}

Number of Mycoplasma pneumoniae detections by age group, 10 countries in Europea and Israel, 2011-2016 (n = 70,191)

Belgium

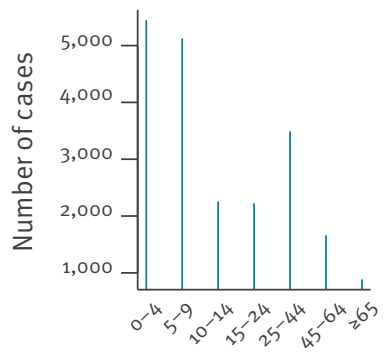

Age group (years)

Greece

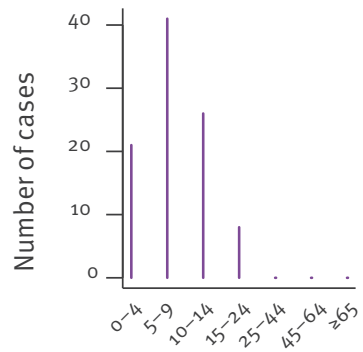

Age group (years)

Slovenia

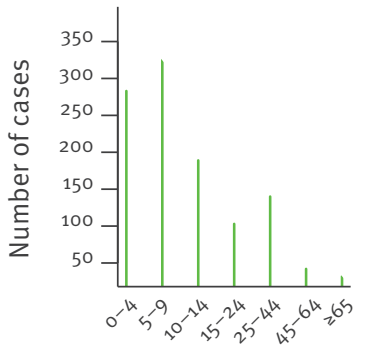

Age group (years)
Denmark

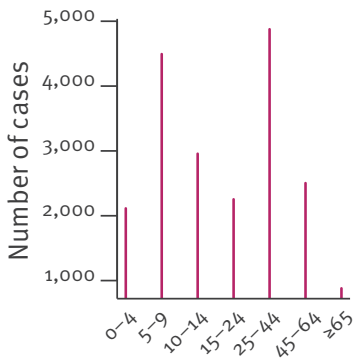

Age group (years)

Hungary

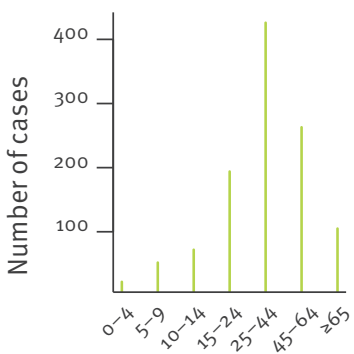

Age group (years)

Sweden

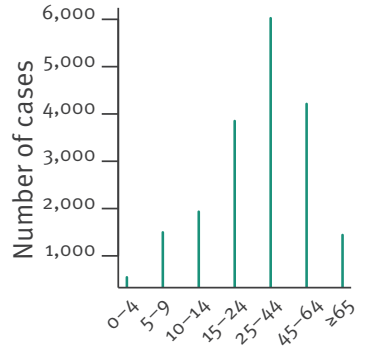

Age group (years)
France

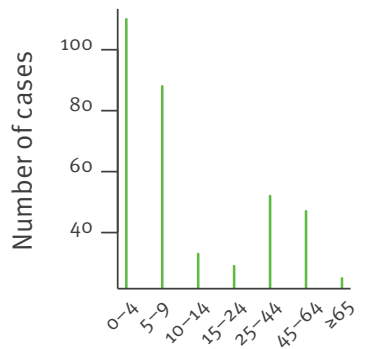

Age group (years)

Ireland ${ }^{b}$

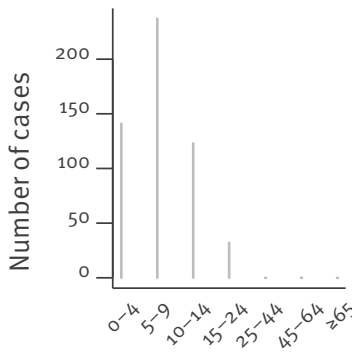

Age group (years)

United Kingdom (excluding Northern Ireland)

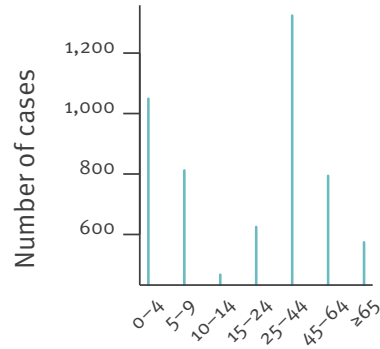

Age group (years)
Germany

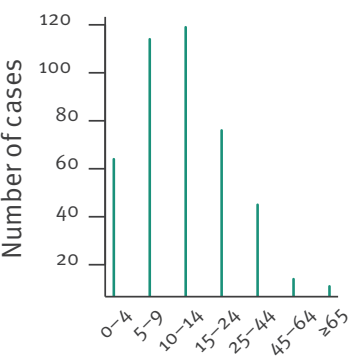

Age group (years)

Israel

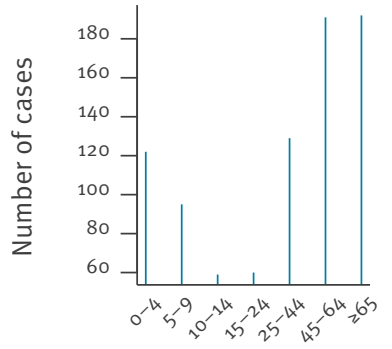

Age group (years)

\footnotetext{
${ }^{\text {a }}$ Age-specific data were not available for Norway.

b Ireland did not test for M. pneumoniae in patients 25 years of age and above.
}

samples during the epidemic period than in the preepidemic period.

\section{Correlation between latitude and epidemic period onset}

When examining the epidemic periods of 2011/12, $2014 / 15$ and $2015 / 16$, a clear association between the country latitude and beginning of the national epidemic period was observed (Figure 4). This was statistically significant for the $2011 / 12$ period ( $p<0.005$; $\left.r^{2}=0.92\right)$ and the $2014 / 15$ period $\left(p<0.005 ; r^{2}=0.84\right)$. However, significance was not achieved during the $2015 / 16$ period $\left(p=0.1 ; r^{2}=0.38\right)$. The association was most apparent during the major epidemic period of 2011/12 when the epidemic period was first noted in Norway $\left(60.4^{\circ} \mathrm{N}\right)$ during epidemic week 22 (calendar week 40 of 2011) and was then observed to start in Israel $\left(31^{\circ} \mathrm{N}\right)$ during epidemic week 43 (calendar week 9 of 2012). There was a lack of an association during 
Correlation between country latitude and epidemic week for Mycoplasma pneumoniae infections, 7 European countries and Israel, epidemic periods 2011/12, 2014/15 and 2015/16
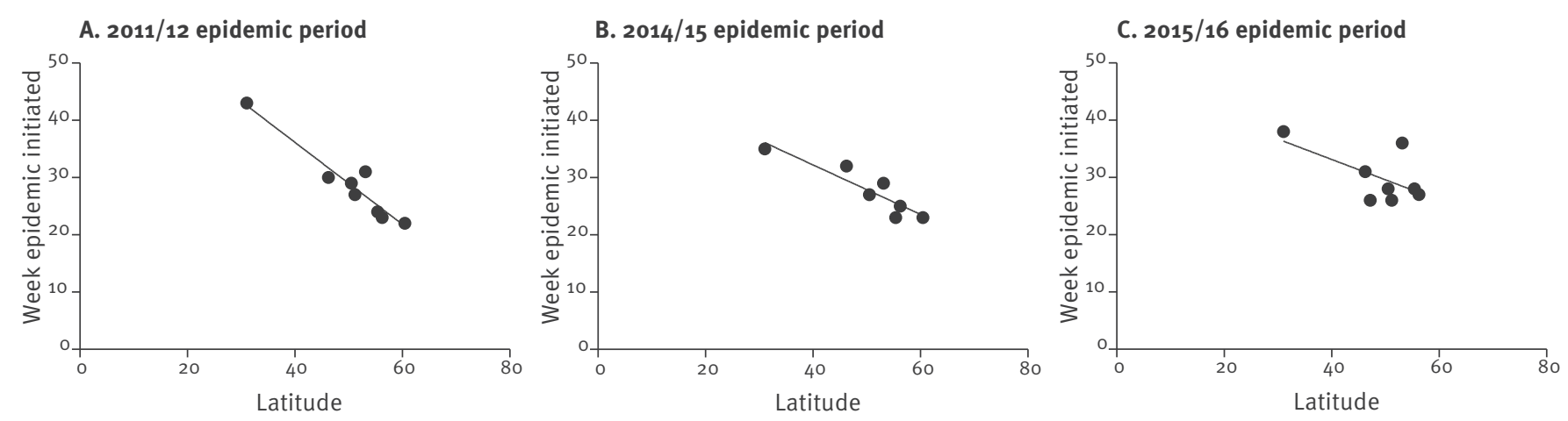

Countries in which epidemic periods began prior to that predicted by the Moving Epidemic Method were removed from the analysis. A statistically significant association between the week in which the country epidemic began and epidemic week number was seen in $2011 / 12$ ( $p$ $\left.<0.005 ; r^{2}=0.92\right)$ and 2014/15 $\left(p<0.005 ; r^{2}=0.84\right)$. No significant association was seen in $2015 / 16\left(p=0.1 ; r^{2}=0.38\right)$.

the non-epidemic periods of 2012/13 and 2013/14 (data not shown).

\section{Discussion}

Our study involved assembling the largest dataset thus far of M. pneumoniae-positive samples and associated data on the methods used to detect $M$. pneumoniae per country. NAATs were the most common method used among the 12 countries. A variety of commercial and in-house methodologies were used in the detection of M. pneumoniae in our study. However, a recent study of 13 assays used across Europe, Israel and the US demonstrated comparable levels of detection of $20 \mathrm{M}$. pneumoniae genomes per reaction [14]. Serological methods were also commonly used to detect $M$. pneumoniae infections. The presence of an IgM response may indicate recent acquisition of infection, but it may be an unreliable marker because of documented longterm persistence of antibodies [15]. Culture-dependent methods were used by three countries. Culture has the benefit of confirming the presence of viable $M$. pneumoniae and may permit phenotypic antimicrobial susceptibility testing. However, because of the considerable time required for growth, up to 4 weeks, it does not provide results within a clinically relevant time period.

Currently, no single method is recommended for routine detection of $M$. pneumoniae, and international guidelines or control materials do not exist. Real-time PCR and serology have previously shown agreement in their ability to detect $M$. pneumoniae among samples (90\% agreement), however, $7 \%$ of patients were PCR positive, with limited evidence of seroconversion [16]. No single test can reliably detect all infections. Therefore, a combined approach utilising both NAAT and serology may help to identify any potential falsenegative results, with NAAT used for acute phase detection [17].
In addition to method of detection, we sought to identify if surveillance for macrolide resistance was routinely undertaken. Routine macrolide resistance monitoring was not systematically in place. This may contribute to the under-detection of resistance or reflect low levels of macrolide resistance reported across Europe [18-20]. High levels of resistance have been noted, for example, in Israel (30\%) [21] and China wherein reported macrolide resistance levels are 90 to $100 \%$ [22,23]. High incidence of macrolide resistance necessitates co-ordinated surveillance across Europe. It would be of benefit to increase physicians' knowledge of macrolide resistance rates and acquisition, as well as an understanding of the patient's recent travel history when considering therapy. In the authors' opinion, co-ordinated international surveillance for macrolide resistance should be considered as macrolides are the current treatment of choice in Europe.

Regardless of the methodology used to detect $M$. pneumoniae, clear seasonal trends were apparent between January 2011 and April 2016, with peaks in infection occurring between the fourth quarter of a year and first quarter of the next. To calculate the epidemic period for each season, the MEM, as described by Vega et al, was used [12]. Three clear epidemics were noted in 2011/12, 2014/15 and 2015/16. M. pneumoniae epidemics have been suggested to occur every 4 to 7 years, lasting for longer than one annual season in some cases $[8,24]$. However, in this study, based on a very large data set, the interval between epidemic occurrence was found to be 3 years from $2011 / 12$ to $2014 / 15$ and 1 year from $2014 / 15$ to $2015 / 16$. The latter epidemic period may reflect a secondary peak of cases within a 2-year epidemic span as previous epidemics have been shown to persist for some time $[5,24]$. Confirmation of circulating genotypes of $M$. pneumoniae from large geographical areas would be of interest to determine the microbiological nature of strains within these and epidemic periods. 
For the major epidemic periods, we sought to determine any changes between the pre-epidemic, epidemic and post-epidemic periods in the reported number of detections in countries reporting both positive and negative data. The greatest rise was seen in Ireland where $18 \%$ of samples were positive for M. pneumoniae in the pre-epidemic period, while $30 \%$ were positive during the epidemic period in 2011/12. In Denmark, France, Slovenia and Sweden, the prevalence in the post-epidemic period was lower than that of the pre-epidemic period in 2011/12. This lower prevalence in the post-epidemic period may reflect over-sampling as a bias resulting from higher prevalence during the epidemic. This may also reflect an increase in the population burden of infection prior to an epidemic. Additional analysis is required to understand if this is the case and if monitoring of levels can be used to predict imminent epidemics.

A notable observation was the pattern of positive detections stratified by age, with detections in all age groups. M. pneumoniae cases are classically seen among children 5 to 14 years of age, with those under 5 years experiencing milder disease [17]. This trend was seen in Germany, Greece, Ireland and Slovenia which skew towards the younger age groups. For Greece, this can be attributed to the acquisition of samples from a tertiary children's hospital in Athens. It should be noted that the skew towards younger age groups seen in Ireland may reflect the nature of only investigating patients up to 25 years of age. An observed peak in infection among the under 14 years age groups was followed by a second peak in the 25 to 44 years age group giving a bimodal distribution in five countries. Finally, a skew to the older age groups was seen in Hungary and Sweden. This observation is not likely to be an artefact of testing methodology whereby older people may be more likely to have existing IgM levels as both countries do not solely rely on serology. The reason for this increased detection in people above 44 years of age in two countries is unknown; it may simply reflect differences in local testing guidelines and routine practice for respiratory screening, or reflect age-based screening practices (e.g. the majority of Hungarian and Swedish samples derived from a population $>25$ years of age).

The final analysis examined the association between the start of epidemic periods as calculated by the MEM model and the geographical location of the country as determined by latitude. Geographical location has not been thought to be of importance in the progression of $M$. pneumoniae infection, but our data suggests that more northern countries experience the start of epidemic periods earlier than those in the south. This association was most clear during the 2011/12 epidemic period, but also held true for the subsequent epidemic periods of $2014 / 15$ and $2015 / 16$. Previous national-based studies have shown epidemics to be polyclonal in nature [25-30]. Establishing whether the microbiological nature of the epidemics across Europe are clonal or not, may be beneficial and influence future sentinel surveillance design. The impact of climatic factors on $M$. pneumoniae infections has yet to be investigated.

\section{Limitations}

A number of limitations are apparent. First, because of the variable reporting methods of each country, specific case definitions were not considered and de-duplication methodologies were not imposed but rather set at submitter-specific level. Overall, reported testing activity or testing-incidence was very different between countries (regions), and conclusions based on analysis across countries must be considered with caution. Ireland did not provide a complete dataset because they only investigated $M$. pneumoniae in patients who were 24 years of age and under. The true number of positive individuals from this population is therefore likely to be underestimated. Second, the data from some countries may not be fully representative of the country as a whole. For example, data from Germany and France was obtained from a single region within each country and how representative this is of national coverage is unknown. Third, the data examining the distribution of detections stratified by age group should be interpreted with a level of caution. The age categories did not contain equal weighting of age groups; for example, there were fewer ages encompassed in the 0 to 4 years group compared with older age groups such as the 25 to 44 years group. Finally, this data did not take the subtypes of $M$. pneumoniae that have been described into account.

\section{Possible clinical impact}

The comparative nature of this study has highlighted a number of interesting points with regards to trends in the testing and epidemiology of $M$. pneumoniae infections. First, cases may be under-detected in countries because of limitations in the age groups examined for the infection. A number of countries showed a skew towards patients > 25 years of age and Belgium, Denmark, France, the United Kingdom (excluding Northern Ireland) and Israel showed a bimodal distribution, suggesting investigations for $M$. pneumoniae, although of importance in young children, should not be restrictive and that consistent testing guidelines are required. It would be beneficial to have an agreed international case definition for infection with M. pneumoniae.

This study also highlights a lack of antimicrobial resistance testing and surveillance of $M$. pneumoniae, resulting in a limited evidence base on resistance to guide therapy. Without active coordinated monitoring, it will not be possible to track changes in resistance profiles and the emergence of high-level macrolide resistant clones. There is an absence of a structured European level surveillance and resistance monitoring for this infection, despite the high levels of resistance in some global areas. In the authors' 
opinion, structured surveillance should be implemented in Europe.

Finally, the observation relating to association between northern latitudes and earlier epidemic start week may suggest the need for another more focused study. It would be interesting to assess the potential value of a rapid, real-time reporting system of $M$. pneumoniae infections across Europe. Such a system could possibly aid in future epidemiological studies and resistance monitoring, and help to predict the $M$. pneumoniae epidemic season throughout the continent.

\section{Conclusion}

As this large study demonstrates, there is currently no standardised method for detecting $M$. pneumoniae infection among patients and macrolide resistance screening is sporadic in European countries despite high levels in some areas globally. A wave of epidemics from more northern latitudes to the more southern ones occurs during epidemic years and the reason for this is not known. There is a need for testing guidelines and standardised international control material for use in testing. The potential value of a co-ordinated international surveillance and macrolide resistance monitoring system needs to be further addressed.

ESCMID Study Group for Mycoplasma and Chlamydia Infections (ESGMAC) Mycoplasma pneumoniae subgroup members not listed as an individual author

Belgium: Nathalie Bossuyt (Service Epidemiology of Infectious Diseases, Sciensano, Brussels); Katrien Lagrou (National Reference Centre for Respiratory Pathogens, University Hospitals Leuven, Leuven)

Cyprus: George Mitis (Immunology Department, Nicosia General Hospital Nicosia; Maria Koliou (Department of Paediatrics, Archbishop Makarios III Hospital, Nicosia)

Czech Republic: Martina Havlickova, Jan Kyncl (National Institute of Public Health, Prague)

Denmark: Hanne-Dorthe Emborg, Marianne Voldstedlund (Statens Serum Institut, Copenhagen)

Germany: Colin Rae MacKenzie (Institute of Medical Microbiology and Hospital Hygiene, Heinrich-HeineUniversity, Duesseldorf)

Greece: Helena C. Maltezou, Theano Georgakopoulou (National Public Health Organization, Athens); Evangelina Petridou, Kirkira Banou (Aghia Sophia Children Hospital, Athens)

Hungary: Eszter Balla (Department of Reference Laboratories, National Public Health Center, Budapest)

Ireland: Jeff Connell, Zoe Yandle, Joanne Moran (University College Dublin, National Virus Reference Laboratory, Dublin); Karen Burns (Health Protection Surveillance Centre, Dublin)

Israel: Ayelet Michael-Gayego, Allon E. Moses (Department of Clinical Microbiology and infectious Diseases, HadassahHebrew University Medical Centre, Jerusalem)
Norway: Gabriel Ånestad, Hans Blystad, Didrik F. Vestrheim (Norwegian Institute of Public Health, Oslo)

Portugal: Filipe Froes (Hospital Pulido Valente and General Directorate of Health Consultant for Pneumology, Lisbon)

Slovenia: Darja Kese (University of Ljubljana, Faculty of Medicine

Institute of Microbiology and Immunology, Ljubljana) and Maja Socan (National Institute of Public Health, Ljubljana)

Spain: Rosa Cano Portero (National Center for Epidemiology, Instituto de Salud Carlos III. CIBERESP), Madrid); Sara Santos Sanz and Berta Suárez Rodríguez (Coordination for Alerts and Public Health Emergencies, Directorate General of Public Health, Ministry of Health, Social Affairs and Equality, Madrid)

Sweden: Anders Ternhag (Karolinska University Hospital and Public Health Agency of Sweden, Stockholm); Christian Giske (Karolinska University Hospital, Stockholm); Karin Tegmark Wisell (Public Health Agency of Sweden, Stockholm)

United Kingdom: Diogo Pereira Marques, Arlene Reynolds, Jim McMenamin (Health Protection Scotland, Glasgow)

\section{Acknowledgements}

We are very grateful to all those who provided the data or nil returns. We would specifically like to thank the following contributors:

Belgium: Sophie Quoilin; Croatia: Sanja Kurečić Filipović and Iva Pem Novosel; Czech Republic: Jitka Castkova and Vratislav Nemecek; Denmark: Sofie Gillesberg Raiser; the Danish Microbiology Data Base (MiBa) Board of representatives for their improvement of the study, the Danish Clinical Microbiology Departments for providing data to MiBa and samples for macrolide resistance examination; staff of the Bacterial PCR Laboratory Statens Serum Institut for examination of samples. England and Wales: Elaine Stanford (Public Health England); Estonia: Irina Filippova; Finland: Ruska Rimhanen-Finne, Markku Kuusi (National Institute for Health and Welfare, Finland); France: Anne-Marie RoqueAfonso; Greece: Kassiani Gkolfinopoulou; Ireland: Niamh Murphy; Italy: Stefania D’Amato and Anna Rita Ciccaglione; Malta: Tanya Melillo; Netherlands: Petra Brandsema (Epidemiology and Surveillance Unit), Marit de Lange (Centre Infectious Disease Control Netherlands (RIVM), Bilthoven), Daan Notermans (RIVM - Centre Infectious Disease Control Netherlands); Norway: Bernardo Guzmán Herrador; Poland: Piotr Polanski and Anna Baumann-Popczyk; Sweden: Andreas Edberg (Klinisk Mikrobiologi Karlstad), Arne Kötz (Klinisk Mikrobiologi Halmstad), Annika Tiveljung Lindell (Karolinska Universitetslaboratoriet Solna), Hilde Riedel ( Klinisk mikrobiologi Uppsala), Kåre Bondeson (Klinisk mikrobiologi Uppsala); Lena Jakobsson (Klinisk mikrobiologi Örebro), Sara Mernelius (Klinisk mikrobiologi Jönköping), Michael Toepfer (Unilabs Skövde), Marianne Bäckman (Klinisk mikrobiologi Aleris), Nina Kamenska (Klinisk mikrobiologi Trollhättan), Claudia Popa (Laboratoriemedicin Västernorrland), AnnChatrine Petersson (Klinisk mikrobiologi Skåne), Camilla Norling (Klinisk mikrobiologi Falun), Baqir Haitham (Klinisk mikrobiologi Linköping); Scotland: Kate Templeton (ESVC) and Rory Gunson (WOSSVC); Slovenia: Sabina Pervić, Ines B. Šimaga, Rok Kogoj; Spain: Elena Vanessa Martínez and Carmen Varela. 
Conflict of interest

None declared.

\section{Authors' contributions}

VC, SU, MB, MI, KL, RD, CB, RNP, SP and OBS conceived the study. $V C$ designed, issued and collated results from the questionnaire. $\mathrm{VC}, \mathrm{MB}$ and $\mathrm{XZ}$ undertook data analysis. $X Z$ and $M B$ undertook modelling and statistics. MB, $X Z, V C$ and SU drafted the manuscript. The ESCMID Study Group for Mycoplasma and Chlamydia Infections (ESGMAC) Mycoplasma pneumoniae subgroup members contributed information on country practice or data for evaluation; with some stating that they have no system or that they have a system but cannot return data. All authors contributed to the manuscript and draft and approved study design.

\section{References}

1. Sánchez-Vargas FM, Gómez-Duarte OG. Mycoplasma pneumoniae-an emerging extra-pulmonary pathogen. Clin Microbiol Infect. 2008;14(2):105-17. https://doi.org/10.1111/ j.1469-0691.2007.01834.x PMID: 17949442

2. Xin D, Mi Z, Han X, Qin L, Li J, Wei T, et al. Molecular mechanisms of macrolide resistance in clinical isolates of Mycoplasma pneumoniae from China. Antimicrob Agents Chemother. 2009;53(5):2158-9. https://doi.org/10.1128/ AAC.01563-08 PMID: 19273685

3. Zhao F, Lv M, Tao X, Huang H, Zhang B, Zhang Z, et al. Antibiotic sensitivity of 40 Mycoplasma pneumoniae isolates and molecular analysis of macrolide-resistant isolates from Beijing, China. Antimicrob Agents Chemother. 2012;56(2):11089. https://doi.org/10.1128/AAC.05627-11 PMID: 22106216

4. Gullsby K, Olsen B, Bondeson K. Molecular Typing of Mycoplasma pneumoniae Strains in Sweden from 1996 to 2017 and the Emergence of a New $\mathrm{P}_{1}$ Cytadhesin Gene, Variant 2e. J Clin Microbiol. 2019;57(6):eooo49-19. https://doi.org/10.1128/ JCM.00049-19 PMID: 30918047

5. Lenglet A, Herrador Z, Magiorakos AP, Leitmeyer K, Coulombier D, European Working Group on Mycoplasm CEuropean Working Group on Mycoplasma pneumoniae surveillance. Surveillance status and recent data for Mycoplasma pneumoniae infections in the European Union and European Economic Area, January 2012. Euro Surveill. 2012;17(5):20075. https://doi. org/10.2807/ese.17.05.20075-en PMID: 22321134

6. Rasmussen JN, Voldstedlund M, Andersen RL, EllermannEriksen S, Jensen TG, Johansen HK, et al. Increased incidence of Mycoplasma pneumoniae infections detected by laboratorybased surveillance in Denmark in 2010. Euro Surveill. 2010;15(45):19708. PMID: 21087593

7. Rastawicki W, Kaluzewski S, Jagielski M, Gierczyski R. Epidemiology of Mycoplasma pneumoniae infections in Poland : 28 years of surveillance in Warsaw 1970-1997. Euro Surveill. 1998;3(10):99-100. https://doi.org/10.2807/esm.03.10.00095en PMID: 12631756

8. Zhang XS, Zhao H, Vynnycky E, Chalker V. Positively interacting strains that co-circulate within a network structured population induce cycling epidemics of Mycoplasma pneumoniae. Sci Rep. 2019;9(1):541. https://doi.org/10.1038/ S41598-018-36325-z PMID: 30679460

9. Statens Serum Institut (SSI). Epidemi med Mycoplasma pneumoniae. [Epidemic with Mycoplasma pneumoniae]. Copenhagen; SSI: October 2016. Danish. Available from: https://www.ssi.dk/aktuelt/nyhedsbreve/epi-nyt/2016/ uge-41---2016

10. Kawai Y, Miyashita N, Kubo M, Akaike H, Kato A, Nishizawa $Y$, et al. Nationwide surveillance of macrolide-resistant Mycoplasma pneumoniae infection in pediatric patients. Antimicrob Agents Chemother. 2013;57(8):4046-9. https://doi. org/10.1128/AAC.00663-13 PMID: 23716043

11. Public Health England (PHE). Annual summary of Mycoplasma pneumoniae laboratory surveillance data, 2016, England and Wales. London: PHE; January 2017. Available from: https://assets.publishing.service.gov.uk/government/ uploads/system/uploads/attachment_data/file/817798/ MycoplasmaAnnualSummary2016.pdf

12. Vega T, Lozano JE, Meerhoff T, Snacken R, Mott J, Ortiz de Lejarazu R, et al. Influenza surveillance in Europe: establishing epidemic thresholds by the moving epidemic method.
Influenza Other Respir Viruses. 2013;7(4):546-58. https://doi. org/10.1111/j.1750-2659.2012.00422.x PMID: 22897919

13. Peuchant O, Ménard A, Renaudin H, Morozumi M, Ubukata $\mathrm{K}$, Bébéar CM, et al. Increased macrolide resistance of Mycoplasma pneumoniae in France directly detected in clinical specimens by real-time PCR and melting curve analysis. J Antimicrob Chemother. 2009;64(1):52-8. https://doi. org/10.1093/jac/dkp16o PMID: 19429926

14. Dumke R, Benitez AJ, Chalker V, Gullsby K, Henrich B, HidalgoGrass $C$, et al. Multi-center evaluation of one commercial and 12 in-house real-time PCR assays for detection of Mycoplasma pneumoniae. Diagn Microbiol Infect Dis. 2017;88(2):111-4. https://doi.org/10.1016/j.diagmicrobio.2017.03.004 PMID: 28318608

15. Nir-Paz R, Michael-Gayego A, Ron M, Block C. Evaluation of eight commercial tests for Mycoplasma pneumoniae antibodies in the absence of acute infection. Clin Microbiol Infect. 2006;12(7):685-8. https://doi.org/10.1111/j.14690691.2006.01469.x PMID: 16774570

16. He XY, Wang XB, Zhang R, Yuan ZJ, Tan JJ, Peng B, et al. Investigation of Mycoplasma pneumoniae infection in pediatric population from 12,025 cases with respiratory infection. Diagn Microbiol Infect Dis. 2013;75(1):22-7. https://doi.org/10.1016/j. diagmicrobio.2012.08.027 PMID: 23040512

17. Waites KB, Xiao L, Liu Y, Balish MF, Atkinson TP. Mycoplasma pneumoniae from the Respiratory Tract and Beyond. Clin Microbiol Rev. 2017;30(3):747-809. https://doi.org/10.1128/ CMR.00114-16 PMID: 28539503

18. Brown RJ, Macfarlane-Smith L, Phillips S, Chalker VJ. Detection of macrolide resistant Mycoplasma pneumoniae in England, September 2014 to September 2015. Euro Surveill. 2015;20(48):30078. https://doi.org/10.2807/1560-7917. ES.2015.20.48.30078 PMID: 26675545

19. Dumke R, Lück C, Jacobs E. Low rate of macrolide resistance in Mycoplasma pneumoniae strains in Germany between 2009 and 2012. Antimicrob Agents Chemother. 2013;57(7):3460. https://doi.org/10.1128/AAC.00706-13 PMID: 23650170

20. Pereyre S, Touati A, Petitjean-Lecherbonnier J, Charron A, Vabret A, Bébéar C. The increased incidence of Mycoplasma pneumoniae in France in 2011 was polyclonal, mainly involving M. pneumoniae type 1 strains. Clin Microbiol Infect. 2013;19(4):E212-7. https://doi.org/10.1111/1469-0691.12107 PMID: 23279613

21. Averbuch D, Hidalgo-Grass C, Moses AE, Engelhard D, Nir-Paz R. Macrolide resistance in Mycoplasma pneumoniae, Israel, 2010. Emerg Infect Dis. 2011;17(6):1079-82. https://doi. org/10.3201/eid/1706.101558 PMID: 21749775

22. Bao F, Qu JX, Liu ZJ, Qin XG, Cao B. [The clinical characteristics, treatment and outcome of macrolide-resistant Mycoplasma pneumoniae pneumonia in children]. Zhonghua Jie He He Hu Xi Za Zhi. 2013;36(10):756-61. PMID: 24433804

23. Zhou Z, Li X, Chen X, Luo F, Pan C, Zheng X, et al. Macrolideresistant Mycoplasma pneumoniae in adults in Zhejiang, China. Antimicrob Agents Chemother, 2015;59(2):1048-51. https://doi.org/10.1128/AAC.04308-14 PMID: 25451048

24. Chalker VJ, Stocki T, Mentasti M, Fleming D, Sadler C, Ellis J, et al. Mycoplasma pneumoniae infection in primary care investigated by real-time PCR in England and Wales. Eur J Clin Microbiol Infect Dis. 2011;30(7):915-21. https://doi. org/10.1007/s10096-011-1176-3 PMID: 21311941

25. Kenri T, Okazaki N, Yamazaki T, Narita M, Izumikawa K, Matsuoka M, et al. Genotyping analysis of Mycoplasma pneumoniae clinical strains in Japan between 1995 and 2005: type shift phenomenon of $M$. pneumoniae clinical strains. Med Microbiol. 2008;57(Pt 4):469-75. https://doi.org/10.1099/ jmm.0.47634-0 PMID: 18349367

26. Kogoj R, Praprotnik M, Mrvič T, Korva M, Keše D. Genetic diversity and macrolide resistance of Mycoplasma pneumoniae isolates from two consecutive epidemics in Slovenia. Eur J Clin Microbiol Infect Dis. 2018;37(1):99-107. https://doi. org/10.1007/s10096-017-3106-5 PMID: 28948376

27. Dumke R, Von Baum H, Lück PC, Jacobs E. Subtypes and variants of Mycoplasma pneumoniae: local and temporal changes in Germany 2003-2006 and absence of a correlation between the genotype in the respiratory tract and the occurrence of genotype-specific antibodies in the sera of infected patients. Epidemiol Infect. 2010;138(12):1829-37. https://doi.org/10.1017/So950268810000622 PMID: 20334729

28. Martínez MA, Ruiz M, Zunino E, Luchsinger V, Aguirre R, Avendaño LF. Identification of $P_{1}$ types and variants of Mycoplasma pneumoniae during an epidemic in Chile. J Med Microbiol. 2010;59(Pt 8):925-9. https://doi.org/10.1099/ jmm.0.018333-0 PMID: 20448063

29. Zhao F, Liu L, Tao X, He L, Meng F, Zhang J. CultureIndependent Detection and Genotyping of Mycoplasma pneumoniae in Clinical Specimens from Beijing, China. PLoS 
One. 2015;10(10):e0141702. https://doi.org/10.1371/journal. pone.0141702 PMID: 26509651

30. Brown RJ, Nguipdop-Djomo P, Zhao H, Stanford E, Spiller OB, Chalker VJ. Mycoplasma pneumoniae Epidemiology in England and Wales: A National Perspective. Front Microbiol. 2016;7:157. https://doi.org/10.3389/fmicb.2016.00157 PMID: 26909073

\section{License, supplementary material and copyright}

This is an open-access article distributed under the terms of the Creative Commons Attribution (CC BY 4.0) Licence. You may share and adapt the material, but must give appropriate credit to the source, provide a link to the licence and indicate if changes were made.

Any supplementary material referenced in the article can be found in the online version.

This article is copyright of the authors or their affiliated institutions, 2020. 